\title{
LICENCIAMENTO AMBIENTAL: DO PROGRAMÁTICO AO PRAGMÁTICO
}

\section{Environmental Licensing: the programmatic to pragmatic}

Luís Carlos Moraes

Centro Universitário UNA, Belo Horizonte, Minas Gerais, Brasil

lcambien@bol.com.br

Artigo recebido em 17/08/2015 e aceito para publicação em 11/08/2016

RESUMO: Este artigo apresenta uma breve discussão teórica sobre a Política Nacional do Meio Ambiente, seus mecanismos de controle e sua aplicabilidade no processo de licenciamento ambiental para empreendimentos imobiliários, uma vez que a indústria de construção civil é considerada uma das mais degradantes do ambiente. O objetivo desse estudo, portanto, é analisar o licenciamento ambiental de empreendimentos imobiliários como instrumento de preservação dos recursos naturais, nos períodos compreendidos entre 2003 a 2014 no município de Resende/RJ. A metodologia utilizada foi à revisão bibliográfica, analise documental e estudo de caso com utilização dos SIG's Resende-Geo e Google Earth para determinar a ocupação irregular do solo situado em áreas consideráveis frágeis. O resultado aponta para o contraditório processo de licenciamento, por parte do Município, como ferramenta de preservação dos recursos naturais, servindo apenas como entrave burocrático para os empreendedores.

Palavras-chave: empreendimentos imobiliários; estudo ambiental; licenciamento ambiental; SIG.

ABSTRACT: This article presents a brief theoretical discussion of the National Environmental Policy, its control mechanisms and their applicability in the environmental licensing process for real estate, since the construction industry is considered one of the most degrading the environment. The aim of this study therefore is to analyze the environmental licensing of real estate projects as preservation tool of natural resources, in the periods from 2003 to 2014 in the municipality of Resende/RJ. The methodology was the literature review, document analysis and use of GIS and Geo Resende- Google Earth to determine the irregular occupation of land situated in fragile considerable areas. The result points to the contradictory licensing process by the municipality, such as preservation tool of natural resources, serving only as a bureaucratic obstacle for entrepreneurs .

Keywords: real estate developments; environmental study; environmental licensing; GIS. 


\section{INTRODUÇÃO}

Este artigo apresenta uma breve discussão teórica sobre a Política Nacional do Meio Ambiente, seus mecanismos de controle e sua aplicabilidade no processo de licenciamento ambiental para empreendimentos imobiliários, tendo como foco o município de Resende (RJ) e seus efeitos na preservação e conservação dos recursos naturais.

De acordo com Primack \& Rodrigues (2006), a biodiversidade ou diversidade ecológica inclui toda interação entre os componentes biótico, formado pelos seres vivos, e os componentes abióticos, como o ar, a água e o clima.

Segundo o art. $2^{\circ}$ da Convenção sobre Diversidade Biológica - $\mathrm{CDB}$, diversidade biológica significa "a variabilidade de organismos vivos de todas as origens, compreendendo, dentre outros, os ecossistemas terrestres, marinhos e outros ecossistemas aquáticos e os complexos ecológicos de que fazem parte; compreendendo ainda a diversidade dentro de espécies, entre espécies e de ecossistemas" (BRASIL, 1992).

A maior diversidade biológica da Terra é encontrada nas regiões Tropicais do mundo. No Brasil, a Mata Atlântica é a segunda maior floresta tropical úmida do Brasil, só comparável à Floresta Amazônica.

Devido a sua elevada biodiversidade e endemismo, o Bioma Mata Atlântica está protegido por lei federal $n^{\circ} 11.428 / 06$, contemplando a preservação e uso sustentável dos recursos naturais bem como o restabelecimento, ou a restauração de suas áreas degradadas, fazendo desta, uma área estratégica para conservação (BRASIL, 2006).

Outro fator relevante para conservação da biodiversidade desse bioma é o estudado pela economia ambiental, ramo da economia que se preocupa com a relação entre as espécies animais e vegetais e os produtos que deles derivam para alimentação, vestuário, moradia e farmacologia, agregando a biodiversidade valor econômico.

Para Primack \& Rodrigues (2006), a economia ambiental que integra economia, ciência ambiental, políticas públicas e valores da diversidade biológica na sua análise econômica, deve conferir valores econômicos diretos e indiretos à biodiversidade e aos recursos naturais.
Neste sentido, a qualidade da água, a proteção do solo, as interações das espécies silvestres com plantações comerciais, a prática do ecoturismo, novos medicamentos, agentes de controle biológico, dentre outros, são alguns dos serviços ambientais que estão entre os valores mencionados anteriormente.

Entretanto, a fisionomia das cidades vem sofrendo alterações devido ao rápido desenvolvimento urbano e a falta de planejamento por parte do poder público. A vegetação urbana está sendo eliminada. Beiras dos córregos, rios, nascentes, áreas brejosas, juntamente com os topos de morros e áreas de maior declividade estão sendo ocupadas, cedendo lugar aos loteamentos. Essas práticas têm contribuído para o aumento da degradação ambiental e eleva a indústria da construção civil ao patamar das atividades que mais degradam o ambiente.

O processo de ocupação do Brasil caracterizou-se pela falta de planejamento e consequente destruição dos recursos naturais. A exploração desordenada do território brasileiro é uma das principais causas da extinção de espécies (IBAMA, 2007).

Segundo Martins (2007), a expansão de áreas urbanas está entre as principais causas de degradação de matas ciliares. A implantação de loteamentos é uma atividade modificadora do meio ambiente, cujo potencial de causar impactos ambientais é relevante, seja no espaço natural, seja no espaço urbano.

Dentre os principais impactos relacionados às indústrias de construção civil cita-se à utilização de recursos naturais, impacto visual e de vizinhança, poluição atmosférica e sonora, impermeabilização do solo, bem como a geração de resíduos e a supressão da vegetação, sendo esta última a grande vilã sob o ponto de vista de conservação dos recursos naturais.

Sendo assim, os empreendimentos imobiliários interferem na paisagem de maneira bastante significativa, portanto, devem estar sujeitos ao licenciamento ambiental, para que se possa garantir a conservação e preservação ambiental descrita na forma da lei e da Resolução CONAMA n ${ }^{\circ}$ 237/97 (BRASIL, 1997).

O fundamento da exigência do licenciamento ambiental reside na possibilidade, constitucional concedida ao Poder Público de impor condições ao exercício do direito de propriedade e do direito ao livre empreendimento, a fim de que a função socioambiental da propriedade seja observada (BRASIL, 1988). 
Assim sendo, segundo a legislação brasileira, o ambiente é classificado como patrimônio público, portanto, deve ser protegido para o bem da coletividade, cabendo ao poder público legislar sobre seu ordenamento, utilização e ocupação (MILARÉ, 2004).

Para tanto, a legislação prevê uma série de instrumentos de controle através dos quais possa ser conferida a possibilidade e regulamentação de toda e qualquer intervenção antrópica realizada sobre o ambiente.

Neste sentido, o licenciamento ambiental constitui um instrumento legítimo de gestão do ambiente, visto que por meio dele, a administração pública exerce o controle sobre as atividades humanas que interferem nas condições ambientais, de modo a encontrar um equilíbrio entre o desenvolvimento social, econômico e a preservação ambiental.

Neste contexto, a relevância deste estudo está na preocupação com o uso e a ocupação irregular do solo no município de Resende, estado do Rio de Janeiro, que vem degradando os recursos naturais, assim como contribuindo para a diminuição da diversidade biológica, visto sua importância para a evolução e manutenção dos sistemas necessários à vida na biosfera, bem como suas influências na oferta dos recursos hídricos, haja vista escassez deste bem no país, principalmente na região sudeste a partir de 2014.

\section{POLÍTICA NACIONAL DE MEIO AMBIENTE}

A relação "leis e ecossistema" têm consequências na biodiversidade. Em termos mundiais, a convenção de 1972 da UNESCO considera os bens naturais como bem comum da humanidade e, por isso, devem ser preservados, pois são únicos e insubstituíveis para qualquer que seja o povo a que pertençam (UNESCO, 1972).

Com a edição da Lei $n^{\circ}$ 6.938/81 (BRASIL, 1981), que estabeleceu a Política Nacional do Meio Ambiente - PNMA, o país passou a ter formalmente uma Política Nacional do Meio Ambiente, um marco legal para todas as políticas públicas de meio ambiente a serem desenvolvidas pelos entes federativos, havendo a partir desta data, pelo menos na teoria, uma integração e uma harmonização dessas políticas tendo como norte os objetivos e as diretrizes estabelecidas na referida lei federal.

A legislação supracitada apresenta definições importantes de meio ambiente, degradação da qualidade ambiental, poluição, poluidor e recursos ambientais e, que instituiu também um importante mecanismo de proteção ambiental denominado avaliação de impacto ambiental (AIA), realizadas através do estudo prévio de impacto ambiental (EIA) e seu respectivo relatório de impacto ambiental (RIMA), instrumentos eficazes e modernos em termos ambientais mundiais, principalmente no que diz respeito à proteção dos ecossistemas e ao uso racional do solo, do subsolo, da água e do ar.

Portanto, entende-se que a legislação em questão visa entre outros a preservação e utilização dos recursos naturais de forma racional cujo instrumento para se alcançar tal objetivo está no licenciamento de atividades efetiva ou potencialmente poluidoras bem como a avaliação de impactos decorrentes de tais atividades.

\section{INSTRUMENTOS DE CONTROLE PARA A GESTÃO AMBIENTAL}

Dentre os instrumentos de controle previstos no art. $9^{\circ}$ da Lei 6.938/81 deu-se ênfase neste estudo na Avaliação de Impactos Ambientais - AIA e ao Licenciamento Ambiental, objeto deste estudo, onde o primeiro é necessário na utilização do segundo instrumento.

Os estudos de impacto ambiental têm algumas características específicas, que muitas vezes não são consideradas na execução do trabalho por fatores de política e poder, prejudicando, pois, os resultados a serem alcançados na proteção aos recursos naturais.

Segundo Medeiros (1995), a AIA deve ser concebida inicialmente como um instrumento preventivo de política pública e só se torna eficiente quando constituir num elemento de auxílio à decisão, uma ferramenta de planejamento e concepção de projetos para que se efetive um desenvolvimento responsável.

As etapas para obtenção das licenças ambientais são: Licença Prévia (LP), concedida na fase preliminar do planejamento do empreendimento ou da atividade aprovando sua localização e concepção, atestando a viabilidade ambiental e estabelecendo os requisitos básicos e condicionantes a serem aten- 
didos nas próximas fases de sua implementação; Licença de Instalação (LI), que autoriza a instalação do empreendimento ou atividade de acordo com as especificações constantes dos planos, programas e projetos aprovados, incluindo as medidas de controle ambiental e demais condicionantes, da qual constituem motivo determinante e a Licença de Operação (LO) que autoriza a operação da atividade ou empreendimento, após a verificação do efetivo cumprimento do que consta das licenças anteriores, com as medidas de controle ambiental e condicionantes determinados para a operação (CONAMA, 1997).

Neste sentido, Jelinek (2010) exemplifica as etapas do processo de licenciamento para empreendimentos imobiliários da seguinte maneira: inicia-se com o levantamento topográfico da área, que deverá ser encaminhado para avaliação da sua viabilidade urbanística e fixação das diretrizes de uso do solo, que têm a função de ordenação do território. Após a manifestação do poder público sobre estas questões, deve suceder-se a avaliação da viabilidade ambiental do empreendimento pelo órgão ambiental competente, que, concluindo positivamente, concederá a licença prévia. Obtidas as diretrizes urbanísticas e ambientais, segue-se a elaboração dos projetos urbanístico e técnicos (abastecimento de água, energia elétrica, esgoto etc.), que deverão ser aprovados pelo Município. Após a aceitação dos projetos e a obtenção da licença ambiental de instalação, definem-se as medidas de controle ambiental e demais condicionantes. Por último, tem cabimento a licença urbanística para construção da obra.

Cabe ressaltar que o Zoneamento Ecológico Econômico - ZEE, segundo o Ministério do Meio Ambiente é um instrumento utilizado para o planejamento e ordenamento do território brasileiro para que as relações econômicas, sociais e ambientais aconteçam de forma responsável (BRASIL, 2002).

Para Santos (2004), essa ferramenta estabelece áreas de planejamento segundo avaliação sistêmica dos elementos naturais e socioeconômicos, cujo resultado é a elaboração de normas de uso e ocupação do solo e do manejo de recursos naturais sob um aspecto conservacionista e de desenvolvimento econômico e social.

Bruner et al. (2001), ao citar ferramentas de preservação e conservação dos recursos naturais, reconhece que a estratégia comprovadamente mais eficaz para promover a manutenção dos ecossistemas naturais é a implantação de sistemas eficientes de áreas protegidas.

Para Faria (1997), as unidades de conservação - UC's constituem a mais importante forma de conservação da biodiversidade, pois mantém intactos os processos evolutivos da Terra sem interferência humana, deixando assim um legado para as gerações futuras.

Sobre a importância das áreas vizinhas às unidades de conservação, Primack \& Rodrigues (2006) colocam que se áreas ao entorno das UC's forem degradadas a biodiversidade dentro das mesmas diminuirá, principalmente se tiverem seu tamanho reduzido, pois, muitas das espécies ultrapassam as fronteiras das áreas em que vivem normalmente em busca de recursos.

Neste sentido o licenciamento ambiental de empreendimentos imobiliários deve contemplar no seu planejamento a redução do isolamento dos fragmentos de vegetação com programas de recuperação da vegetação nativa e estimulando práticas que se mostrem amigáveis à conservação, conforme apregoa a Lei Federal n ${ }^{\circ} 11.428 / 2006$ (BRASIL, 2006).

Outra importante ferramenta de conservação e preservação dos recursos naturais está inserida na Lei Federal $n^{\circ} 12.651 / 12$ que definiu as Áreas de Preservação Permanente- APP's. Dentre elas encontram-se as nascentes, topos de morros e encostas, áreas brejosas e margens de corpos hídricos, todas consideradas como áreas frágeis e, por isso, sujeitas a um regime jurídico que deve atentar ao interesse público.

A ocupação indiscriminada e sem critérios dessas áreas causam impactos negativos ao ambiente natural, como erosão, alagamentos, assoreamento de cursos d'água e eliminação de nascentes, além de afetar na quantidade e qualidade dos recursos hídricos.

\section{MATERIAL E MÉTODO}

A região inventariada refere-se ao município de Resende/RJ, no período compreendido entre janeiro de 2009 a julho de 2014. Além da revisão bibliográfica e da analise documental utilizou-se de Sistemas de Informações Georeferenciadas: SIG's Resende- Geo e Google Earth. O Resende-Geo é uma ferramenta de avaliação de impacto ambiental, um SIG desenvolvi- 
do para gestão territorial que permite trabalhar com dados espaciais alfanuméricos e que disponibiliza ferramentas funcionais para análise, consulta, edição e reestruturação de dados, geração de relatórios e associação de dados externos. É um aerofotogramétrico de alta resolução espacial (pixel $=25 \times 25 \mathrm{~cm}$ ) que recobre área urbana de $85 \mathrm{~km}^{2}$.

Verificou-se dentre os loteamentos licenciados e em execução no município aqueles que contemplavam os seguintes critérios: estar localizado em topo de morro nas proximidades de um corpo hídrico, nascente e área brejosa, áreas consideradas de preservação permanente
- APP. Assim, obedecendo a esses critérios e, para que se possa dar ênfase ao objeto de estudo, foram escolhidos três empreendimentos considerados mais críticos no tocante aos aspectos ambientais citados, aqui intitulados empreendimentos A e B (Figura 01). Para melhor embasar a caracterização da área de estudo sob a ótica da pressão antrópica, evidenciando o hiato existente entre a teoria e a prática do processo de licenciamento imobiliário, bem como subsidiar as análises dos resultados, comparou-se imagens do empreendimento "A", na fase de terraplanagem e a evolução da ocupação irregular do solo do empreendimento "B".

Figura 1 - Vista área de Resende e contributivos do rio Paraíba do Sul, em destaque.

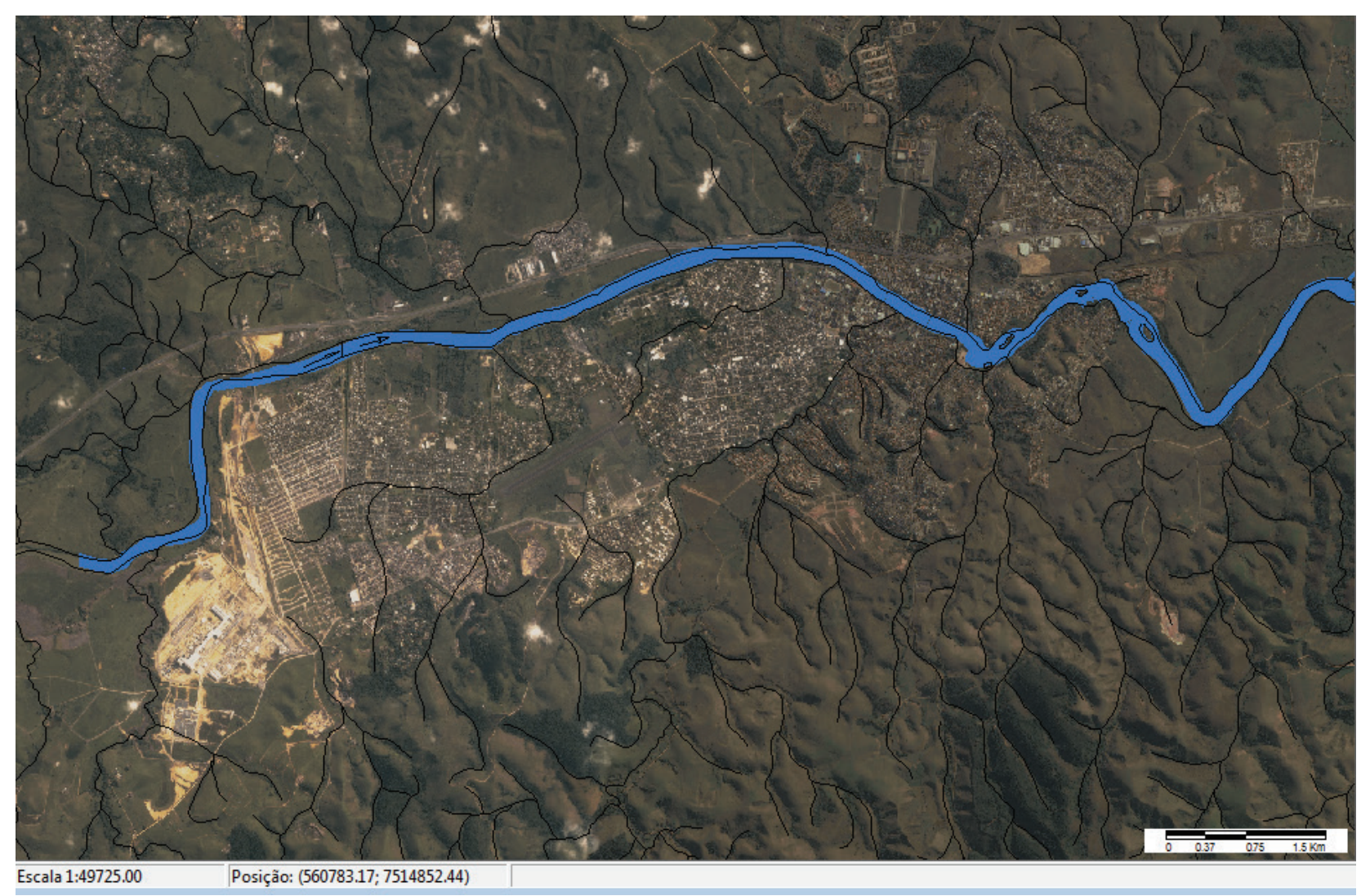

Fonte: Resende-Geo, 2009.

Ressalta-se que a terraplanagem é a fase que provoca maior degradação ambiental, visto que se trata do movimento de terra necessário para adequar os terrenos para a construção da obra, constituindo-se em um conjunto de operações de escavação, transporte, disposição e compactação de terras, gerando cortes e aterros no empreendimento. Essa prática deixa o solo sem proteção superficial, suscetíveis a intensos processos erosivos, que aliado as chuvas pode provocar assoreamento dos corpos hídricos, favorecendo a ocorrência de inundações. A supressão vegetal resulta diretamente em prejuízo à cobertura vegetal e a biodiversidade local. 


\section{RESULTADO E DISCUSSÃO}

\section{Biodiversidade}

O Instituto de Pesquisa Jardim Botânico do Rio de Janeiro (2010) aponta 35 espécies endêmicas, 90 espécies vulneráveis e 4 ameaçadas de extinção entre os municípios de Itatiaia e Resende, ambas no estado do Rio de Janeiro. Neste sentido, a SOS Mata Atlântica (2008) aponta Resende como área de prioridade extremamente alta para conservação do bioma Mata Atlântica, uma vez que existem somente $22 \%$ de área remanescente de cobertura original. Sendo assim, uma vez que Resende está entre dois Parques Nacionais - PARNA, mister se faz uma conexão com a área do PARNA do Itatiaia e o PARNA Serra da Bocaina (SP) pois um dos maiores riscos para os remanescentes de mata é a falta de ligação entre um fragmento e outro, reduzindo o chamado "efeito de borda".

De acordo com Pinheiro \& Viana (1998), quando se interligam os fragmentos através de corredores de biodiversidade, aumenta-se o fluxo de animais e sementes e, portanto, a colonização das áreas degradadas pelas espécies de plantas e animais presentes nos fragmentos florestais.

Neste sentido a lei de proteção à vegetação nativa da Mata Atlântica prevê o fomento, por parte do poder público, do plantio de espécies florestais visando o controle do efeito borda. Além do exposto, ressalta-se que as florestas são fundamentais para assegurar o equilíbrio do clima e parte vital do ciclo da água.

\section{Recursos Hídricos}

Segundo Associação Pró-Gestão das Águas da Bacia Hidrográfica do Rio Paraíba do Sul - AGEVAP (2006), cerca de 50\% das florestas existentes na bacia do rio Paraíba do Sul encontra-se em Unidades de Conservação, como o Parque Nacional de Itatiaia, o Parque Nacional da Serra dos Órgãos e a Reserva da Biosfera da Mata Atlântica. Unindo os três estados da bacia, destaca-se a APA Federal da Serra da Mantiqueira.

No Plano de Recursos Hídricos da Bacia do Rio Paraíba do Sul, realizado pela AGEVAP, a indicação de áreas prioritárias para recuperação e conservação na bacia do Paraíba do Sul resultou da análise integrada das condições de cobertura florestal, vulnerabilidade à erosão, disponibilidade hídrica e localização de mananciais nas sub-bacias.

Neste sentido, à medida que aumentam os efeitos da degradação ambiental sobre a disponibilidade de recursos hídricos e sobre os corpos d'água em geral, a gestão integrada da bacia hidrográfica assume importância cada vez maior.

Os maiores índices pluviométricos da bacia do Paraíba do Sul ocorrem no trecho paulista da serra do Mar, nas regiões do maciço do Itatiaia e seus contrafortes e na Serra dos Órgãos, trecho da Serra do Mar que acompanha a Região Serrana do Estado do Rio de Janeiro, onde a precipitação anual chega a ultrapassar $2.000 \mathrm{~mm}$, o que faz com que a área da Bacia Sedimentar de Resende, seja considera de relevante importância em termos de favorabilidade hidrogeológica para a Bacia do Paraíba do Sul. A produtividade do sistema aquífero desta região é alta, chegando a vazões da ordem de $30 \mathrm{~m} 3 / \mathrm{h}$ a $50 \mathrm{~m} 3 / \mathrm{h}$, variando de acordo com o local (CASTRO, 2000).

Sendo assim e de acordo com a Política Nacional de Recursos Hídricos considera-se que ações de recuperação e conservação das bacias hidrográficas principais devem ser voltadas para as suas sub-bacias, no caso em tela, a do rio Paraíba do Sul.

No entanto, o que se nota é a total falta de comprometimento, por parte do poder público local, com a preservação dos recursos hídricos. Observa-se na Figura 02, empreendimento "A", datado da época anterior a analise do licenciamento ambiental, uma vez que o empreendimento foi aprovado em meados de 2012, que a área em questão apresenta 4 nascentes, córrego perene, lagoas naturais, área brejosa além de topo de morro que sustenta essa dinâmica hídrica. 
Figura 2 - Empreendimento "A" antes da fase de terraplanagem.

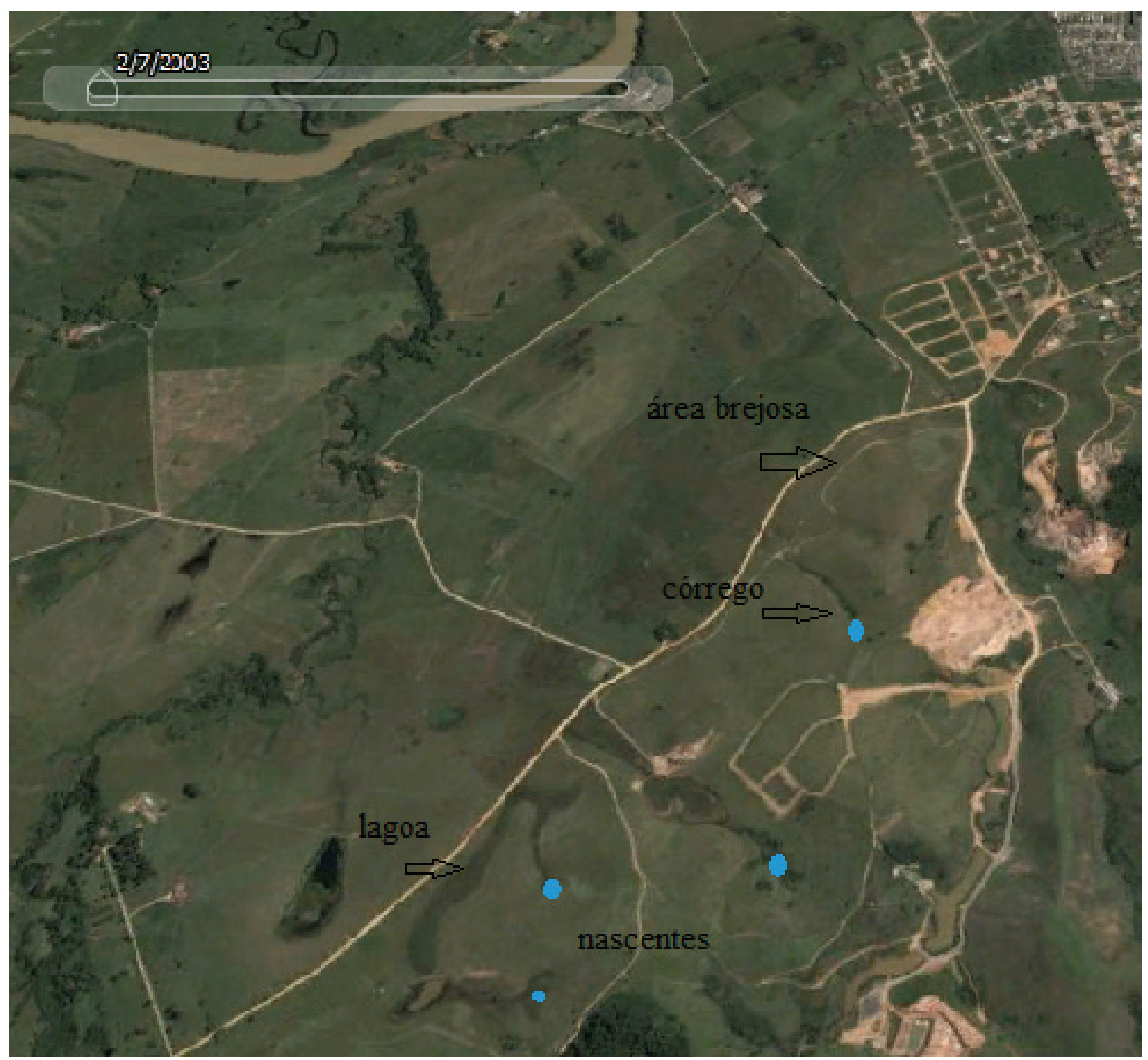

Fonte: Google Earth, 2003.

A Figura 3 demonstra que na fase de implantação do empreendimento "A" (terraplanagem) já se constata supressão das nascentes com aterro da área brejosa, além do decapeamento do topo do morro e de sua encosta.

Como consequência deste decapeamento tem-se a alteração do regime hídrico da bacia, já que a vertente orienta a perenidade - direta e indireta- dos cursos d'água pela ação geomorfológica, e o aumento do impacto erosivo associado ao escoamento de materiais provenientes da encosta no corpo hídrico, causando assoreamento deste.

A apropriação desordenada de áreas, consideradas restritivas, como relevo íngreme ou faixas de inundação, pode gerar impactos de elevado custo socioeconômico ambiental. Cabe ressaltar que a Lei Federal 12.651/12 no seu art. $4^{\circ}$ considera APP as faixas marginais de qualquer curso d'água natural em largura mínima de $30 \mathrm{~m}$ para os cursos d'água de menos de $10 \mathrm{~m}$ de largura, além de distanciamento de $30 \mathrm{~m}$ para lagoas naturais em zonas urbanas e de $50 \mathrm{~m}$ para nascentes. 
Figura 3 - Fase de terraplanagem do empreendimento "A"

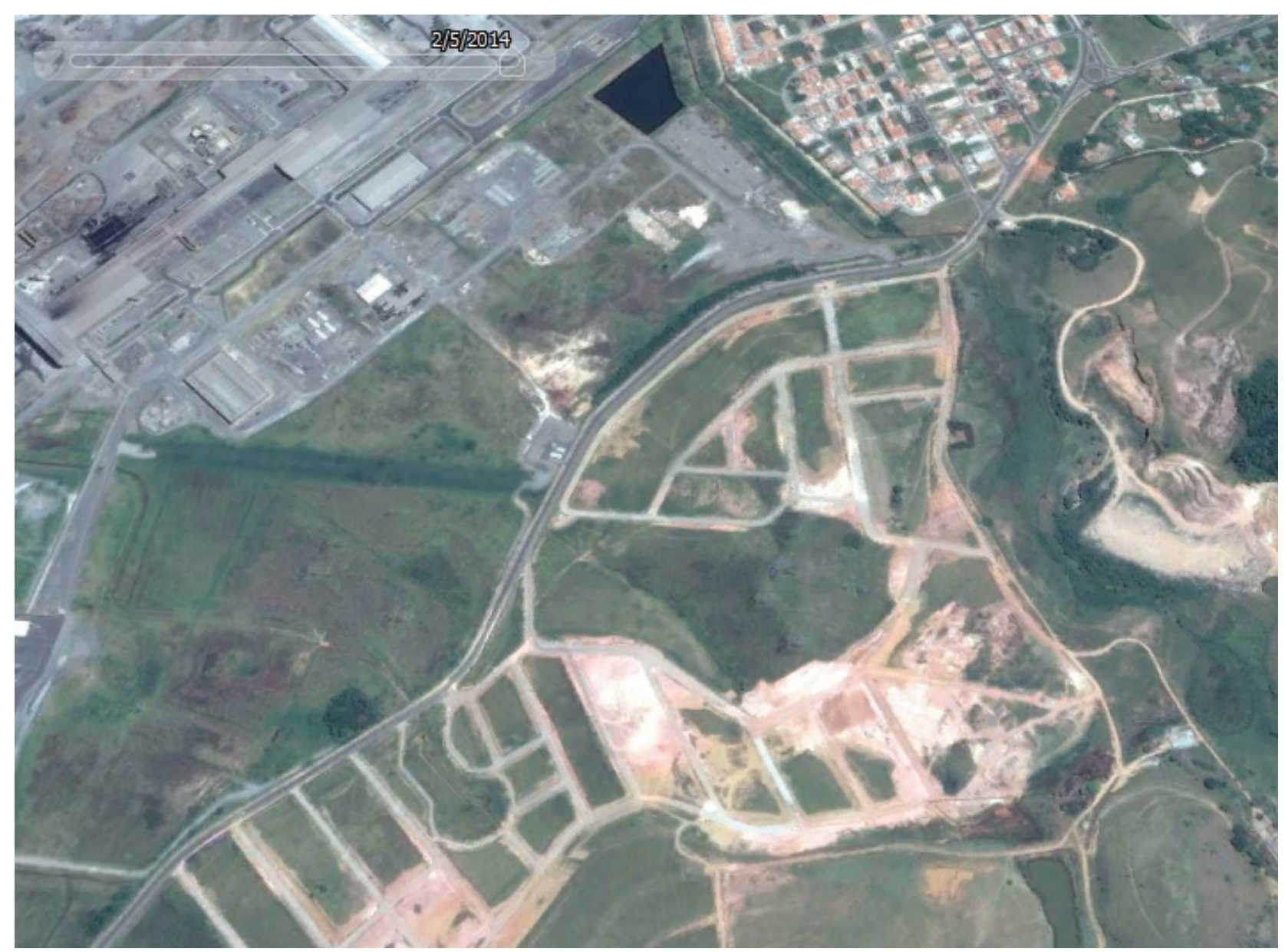

Fonte: Google Earth, 2014.]

A Figura 4 evidencia construções em APP, indo de encontro à lei supracitada, no seu artigo $\mathrm{n}^{\circ} 4$ quanto ao afastamento de $30 \mathrm{~m}$ para os cursos d'água com até $10 \mathrm{~m}$ de largura bem como para lagoas em áreas urbanas, fato este não respeitado ao longo do tempo, como representado na Figura 5. 
Figura 4 - Início de ocupação irregular de APP

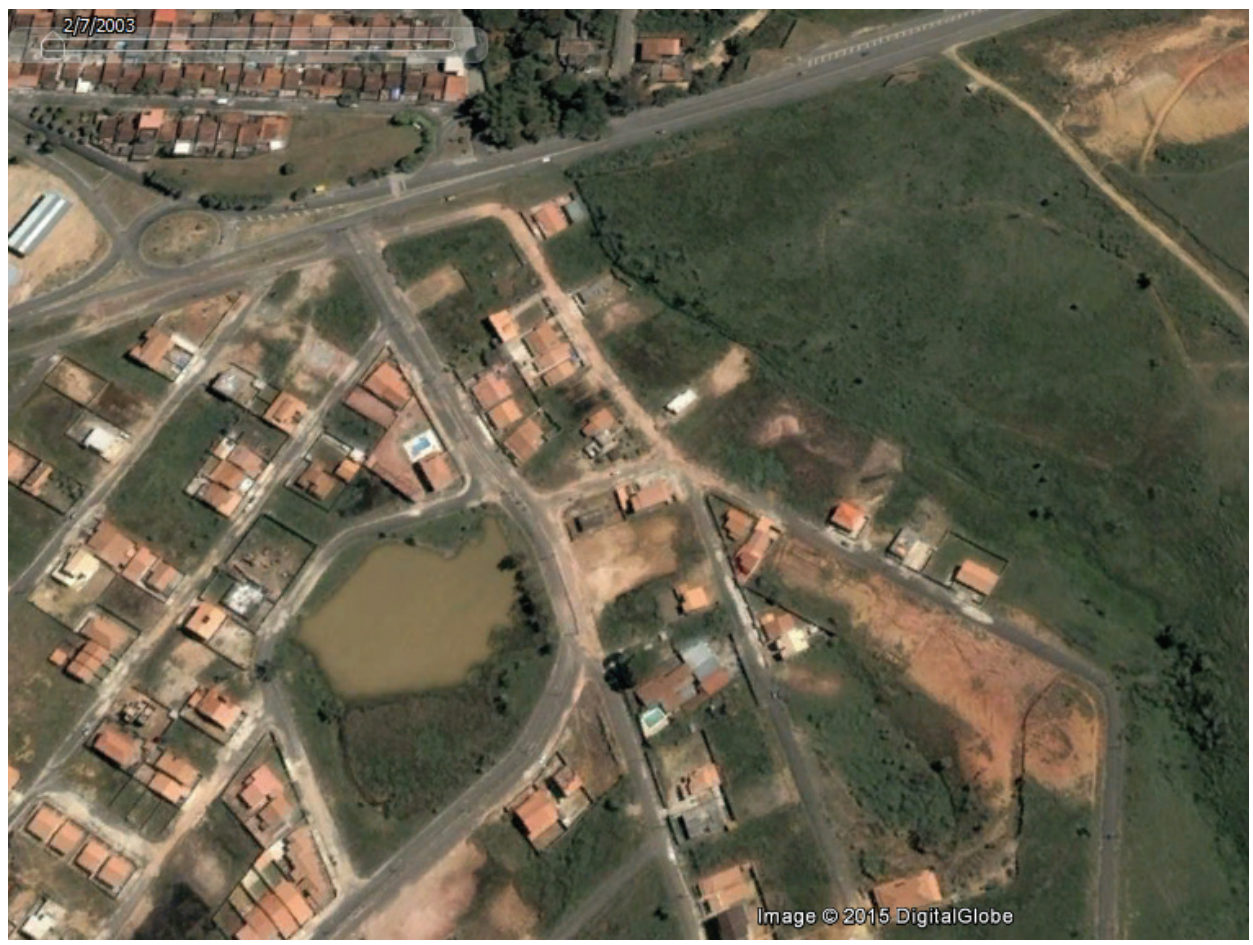

Fonte: Google Earth, 2003.

Figura 5 - Avanço da ocupação irregular em APP.

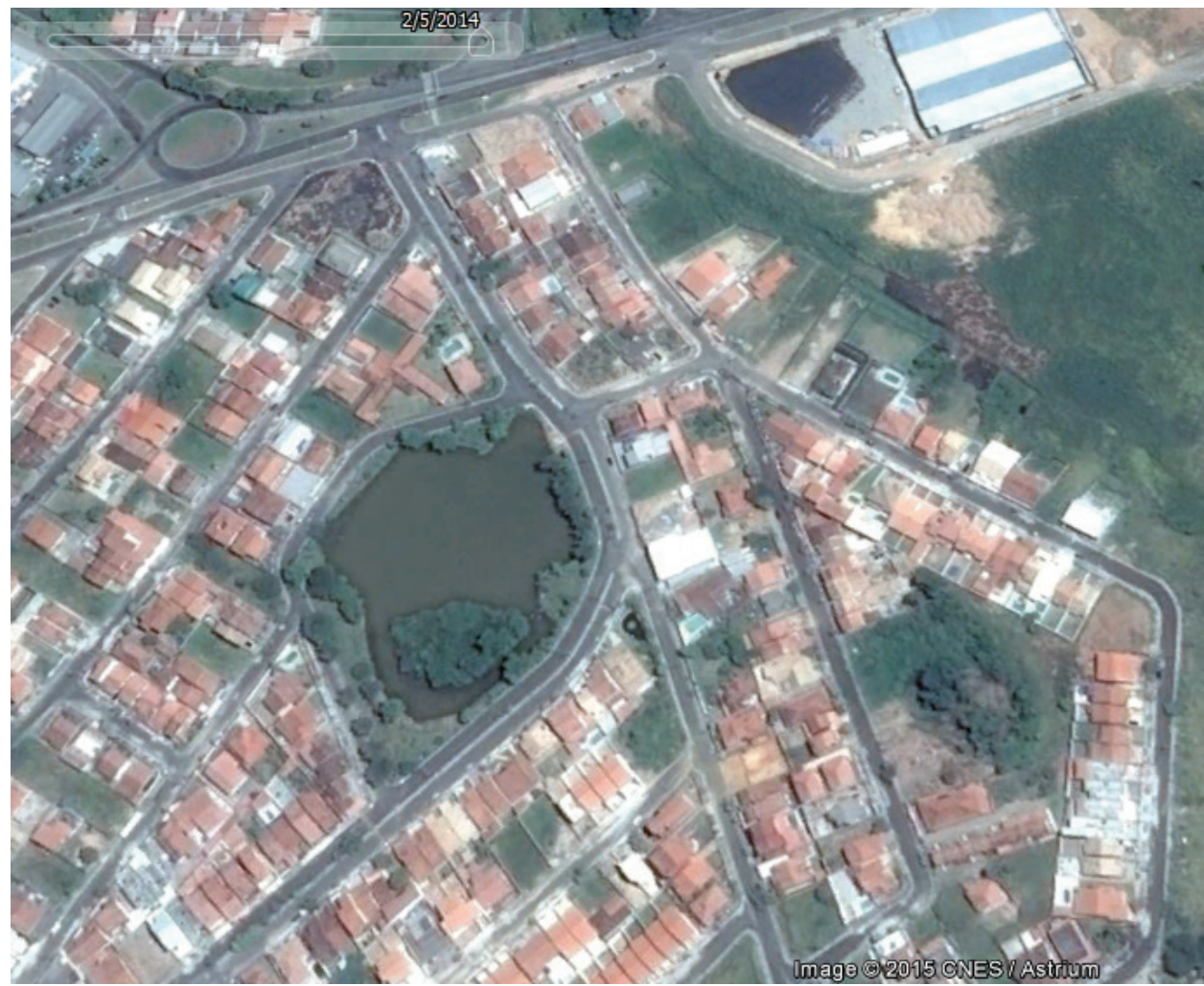

Fonte: Google Earth, 2014. 
Constatou-se também a canalização do córrego, compactação do solo e supressão de mata ciliar, conforme Figura 6, favorecendo a ocupação da área considerada de preservação permanente em detrimento a preservação e conservação dos recursos naturais. Segundo a Lei Federal n ${ }^{\circ} 11.428 / 06$ o corte e a supressão de vegetação primária ou nos estágios avançado e médio de regeneração do Bioma Mata Atlântica fica vedado quando exercer a função de proteção de mananciais ou de prevenção e controle de erosão, dentre outros.

Figura 6 - Canalização do corpo hídrico.

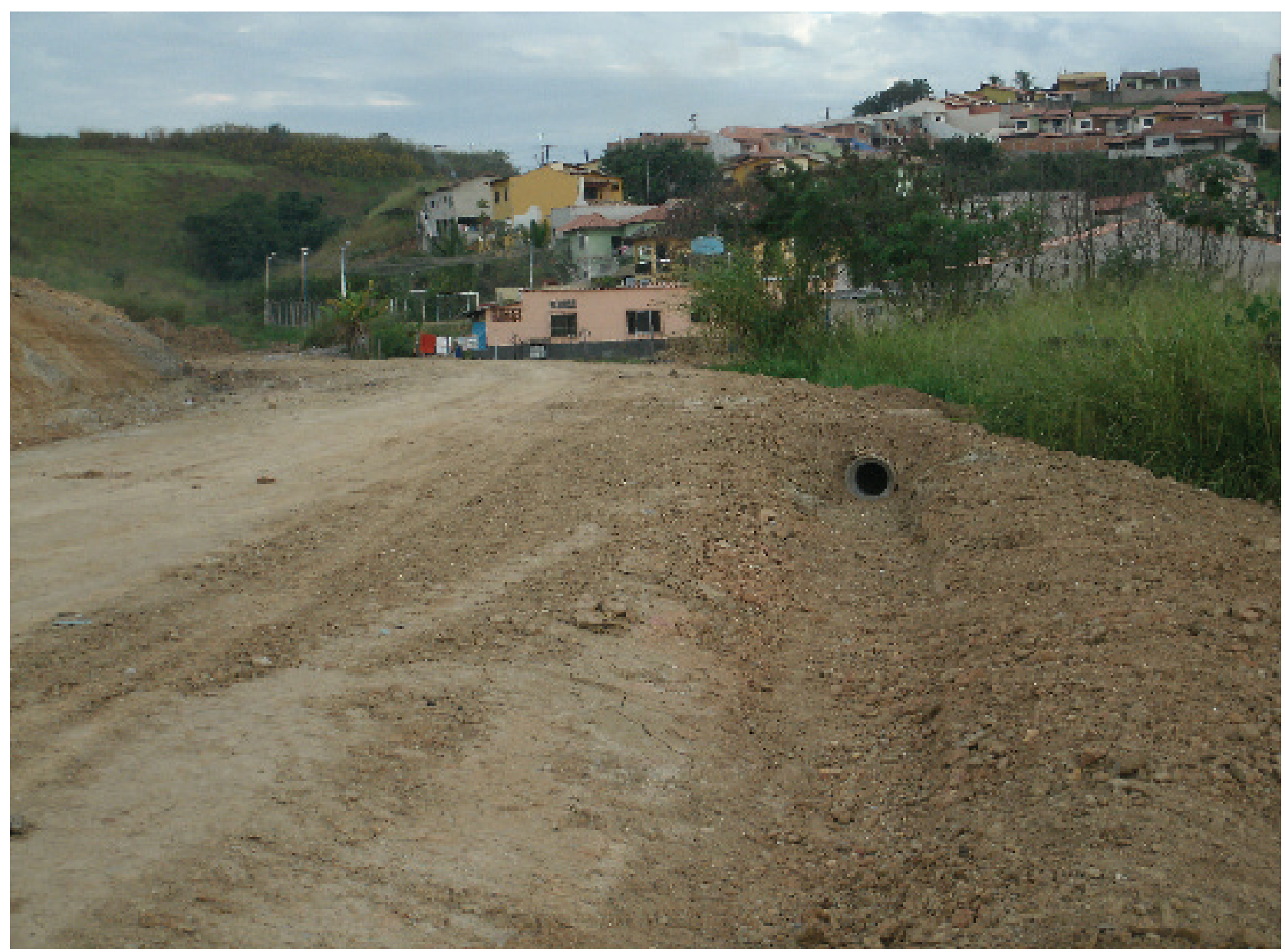

Fonte: Luís, 2012.

Segundo Mendonça (1994), a impermeabilização do solo e a canalização de córregos; muito comum em todas as cidades do país, visto a morosidade do poder público em solucionar os problemas de tratamento de esgoto que correm a céu aberto nos corpos hídricos e, por isso, mais fácil canalizar os mesmos, estão entre os fatores mais evidentes da modificação do clima local das cidades, além disso, fere o Código de Águas (BRASIL, 1934), que é a restrição mais antiga de uso do solo urbano por construção civil e, que trata da proibição de qualquer edificação que possa impedir ou atrapalhar o livre curso das águas.

\section{CONCLUSÕES}

Como resultado do presente estudo, a pesquisa de campo mostrou, sem exceção, o desrespeito às leis ambientais e a consequente falta de comprometimento com a conservação dos recursos naturais, uma vez que os empreendedores suprimiram vegetação ripária, soterraram nascentes e área brejosa além de compactar o solo em APP. 
Portanto, concluiu-se que o processo de licenciamento ambiental no município de Resende (RJ) para empreendimentos imobiliários, no período entre os anos de 2009 a 2014, não contemplam as exigências técnicas e legais para a avaliação de impactos ambientais, desconsiderando, pois, a preservação dos recursos naturais.

Em relação ao processo de licenciamento ambiental e com base no instrumento legal utilizado pelo município de Resende (RJ) e pelas constatações in loco, para a conservação real dos recursos naturais e da qualidade de vida dos indivíduos que buscam tais empreendimentos, sugere-se:

- Aplicação da legislação em toda a sua complexidade para o ambiente a ser licenciado.

- Cumprimento efetivo dos projetos apresentados no que diz respeito às medidas mitigadoras e compensatórias, neles apresentadas.

- Apresentação de planos de recuperação de áreas degradadas, conforme legislação vigente, baseadas no inventário faunístico e florístico, pois, estes constituem ferramentas essenciais para preservação dos recursos bióticos e abióticos.

- Cumprimento de todas as legislações pertinentes ao assunto, principalmente a Lei Federal ${ }^{\circ} 11.428 / 06$, que estabelece regras próprias de competência para a supressão de vegetação do bioma Mata Atlântica, de modo que o município, apenas, poderá autorizar a supressão de vegetação quando se tratar de vegetação secundária em estágio médio de regeneração, situada em área urbana e em caso de utilidade pública ou interesse social, sendo necessária anuência prévia do órgão ambiental estadual competente. Nos demais casos, a competência para deliberação de supressão de vegetação, referente a este bioma é apenas do Estado e não do Município, inclusive, em se tratando de loteamento ou edificações para empreendimentos imobiliários.
- Outro aspecto relevante, no tocante ao processo de licenciamento ambiental dos empreendimentos imobiliários diz respeito à necessidade de elaboração de diversos estudos de viabilidade ambiental nas áreas possivelmente afetadas, como Estudos Prévios de Impacto Ambiental, EIA, Estudos de Impacto de Vizinhança, Uso e Ocupação do Solo dentre outros.

Espera-se que estas medidas fortaleçam os sistemas de licenciamento, fiscalização e monitoramento de atividades relacionadas com a biodiversidade, crie capacidade no órgão responsável pelo licenciamento ambiental para avaliação de impacto sobre esta, apoie estudos de impacto da fragmentação de habitats sobre a manutenção da fauna e flora e identifique e avalie as políticas públicas que afetam negativamente a diversidade biológica, ratificando desta forma os objetivos previstos no Decreto Federal n.4.339/2002, que institui princípios e diretrizes para implementação da Política Nacional da Biodiversidade, bem como fazendo com que o licenciamento ambiental deixe de ser visto por muitos empreendedores e ambientalistas como obstáculo para ser visto como instrumento de efetiva proteção dos recursos naturais.

\section{REFERÊNCIAS}

Associação Pró-Gestão das Águas da Bacia Hidrográfica do Rio Paraíba do Sul - AGEVAP Plano de Recursos Hídricos da Bacia do Rio Paraíba do Sul. Resende, 2006. Disponível em: $<$ http://www.ceivap. org.br/downloads/PSR-010-R0.pdf > . Acesso em: 16 jul. 2015.

BRASIL. Resolução n ${ }^{\circ}$ 237, de 19 de dezembro de 1997. Dispõe sobre a revisão e complementação dos procedimentos e critérios utilizados para o licenciamento ambiental. Conselho Nacional do Meio Ambiente-CONAMA. Brasília, DF, 19 dez.1997.

BRASIL. Decreto n ${ }^{\circ}$. 24.643, de 10 de julho de 1934. Decreta o Código de Águas. Presidência da República. Brasília, DF, 10 jul. 1934. 
BRASIL. Decreto n4.297, de 10 de julho de 2002. Regulamenta o art. 9o, inciso II, da Lei no 6.938, de 31 de agosto de 1981, estabelecendo critérios para o Zoneamento Ecológico-Econômico do Brasil. Ministério do Meio Ambiente. Brasília, DF, 10 jul. 2002.

BRASIL. Lei no 11.428 , de 22 de dez. de 2006. Dispõe sobre a utilização e proteção da vegetação nativa do Bioma Mata Atlântica, e dá outras providencias. Presidência da República. Brasília, DF, 2006.

BRASIL. Lei $\mathrm{n}^{\circ}$ 2.519, de 16 de março de 1998. Promulga a Convenção sobre Diversidade Biológica, assinada no Rio de Janeiro, em 05 de junho de 1992. Presidência da República. Brasília, DF, 1998.

BRASIL. Lei n ${ }^{\circ}$ 6.938, de 31 de agosto de 1981. Dispõe sobre a Política Nacional do Meio Ambiente, seus fins e mecanismos de formulação e aplicação, e dá outras providências. Presidência da República. Brasília, DF: 1981.

BRUNER, A; GULLISON, R. E; RICE, R. E; FONSECA, G. A. B. Effectiveness of parks inprotecting tropical biodiversity. Science, v. 291, pp.125-128, 2001. DOI: $10.1126 /$ science.291.5501.125

CASTRO, F. G. Caracterização Hidrogeológica e Hidroquímica da Bacia Sedimentar de Resende (RJ). 2000. 130 f. Dissertação (Mestrado em Geologia) Programa de Pós-graduação em Geologia, Universidade Federal do Rio de Janeiro. Rio de Janeiro, 2000.

FARIA, H. H. Avaliação da Efetividade do Manejo de Unidades de Conservação: como proceder? In: Congresso Brasileiro de Unidades de Conservação. Curitiba, RNPUC, SEMA, FBPN, Anais... v. 1, pp. 478-499, 1997.

INSTITUTO BIOMAS. Estratégias e ações para conservação da Biodiversidade no Estado do Rio de Janeiro. Rio de Janeiro, 2009.

INSTITUTO DE PESQUISA JARDIM BOTÂNICO DO RIO DE JANEIRO. Disponível em: <http://www. jbrj.gov.br/pesquisa/div_tax/briofitas/mapas.htm>. Acesso em: 12 dez. 2010.
JELINEK, R. Licenciamento ambiental e urbanístico para o parcelamento do solo urbano. Disponível em: $<$ http://www.mp.go.gov.br/portalweb/hp/9/docs/doutrinaparcel_19.pdf>. Acesso em: 16 jul. 2015.

MARTINS, S. V. Recuperação de Matas Ciliares. 2.ed. Viçosa, MG, 2007.

MEDEIROS, J. D. Avaliação de Impacto Ambiental In: Reunião Anual da Sociedade Brasileira para o Progresso da Ciência, Anais... 47, 1995.

MENDONÇA, F. A. O Clima e o Planejamento Urbano das Cidades de Porte Médio e Pequeno: Proposições Metodológicas para Estudo e sua Aplicação à Cidade de Londrina/PR. 1994, 322 f. Tese (Doutorado em Geografia Física) - Faculdade de Filosofia, Letras e Ciências Humanas, USP, São Paulo, 1994.

MILARÉ, E. Direito do Ambiente: doutrina - prática - jurisprudência - glossário. Revista dos Tribunais, São Paulo, 2004.

PINHEIRO, L.A. F. V; VIANA, V. M. Conservação da biodiversidade em fragmentos florestais. IPEF, v. 12, n. 32, pp. 25-42, 1998.

PRIMACK, R. B; RODRIGUES, E. Biologia $d a$ Conservação. Londrina: Planta, 2006.

SANTOS, R. F. dos. Planejamento Ambiental: Teoria e Prática. Oficina de Textos. São Paulo, 2004.

SOS MATA ATLANTICA. Mata Atlântica. Mata Atlântica. Disponível em: <http://www.sosmatatlantica.org.br/index.php? section=info\& action=mata $>$. Acesso em: 10 out. 2010. 